DOI: https://doi.org/10.24867/10GI02Vujatov

\title{
ANALIZA FINANSIJSKIH PERFORMANSI U FUNKCIJI VREDNOVANJA KAPITALA MEDICINSKE LABORATORIJE JUGOLAB
}

\section{THE ANALYSIS OF FINANCIAL PERFORMANCES IN THE FUNCTION OF CAPITAL VALUATION OF MEDICAL LABORATORY JUGOLAB}

\author{
Predrag Vujatov, Fakultet tehničkih nauka, Novi Sad
}

\section{Oblast - INDUSTRIJSKO INŽENJERSTVO I MENADŽMENT}

Kratak sadržaj - Predmet istraživanja je analiza finansijskih performansi u funkciji vrednovanja kapitala. Prvi deo rada se zasniva na teorijskim postavkama o analizi finansijskih izveštaja i proceni vrednosti kapitala, dok se drugi deo rada fokusira na praktičan primer analize $i$ projekcije finansijskih izveštaja kao i procene vrednosti kapitala medicinske laboratorije Jugolab.

Ključne reči: diskontna stopa, finansijski izveštaji, kapital, procena

Abstract - Subject of this paper is analysis of financial performances in function of valuation of capital. First part is based on theoretical assumptions of analysis of financial reports and valuation of capital, while second part is based on practital example of analysis and financial report projections and valuation of capital of medical laboratory Jugolab.

Keywords: discount rate, financial report, capital, valuation

\section{UVOD}

Procena vrednosti kapitala preduzeća prisutna je kao fenomen u svetu već dugi niz godina, a u Republici Srbiji više od 20 godina. Postoji veliki broj razloga za procenu vrednosti kapitala poput prodaje ili kupovine preduzeća, spajanja ili razdvajanja preduzeća, sudskih sporova, u slučaju privatizacije itd. U okviru procene vrednosti kapitala najveći značaj pridaje se analizi i projekciji finansijskih izveštaja kao i utvrđivanju diskontne stope.

\section{POJMOVNO ODREĐENJE PROCENE VREDNOSTI KAPITALA}

Procena vrednosti kapitala je postupak koji rezultira davanjem mišljenja o vrednosti određenog svojinskog interesa u preduzeću na određeni dan. Svojinski interes se može odnositi na sopstveni kapital preduzeća, odnosno na njegovu neto imovinu ili na ukupno investirani kapital, koji pored sopstvenog, obuhvata i pozajmljeni kapital. U oba slučaja procena podrazumeva primenu specifične metodologije, standarda i etičkih pravila, a svrha procene se razlikuje [1].

\section{NAPOMENA:}

Ovaj rad je proistekao iz master rada čiji mentor je dr Jelena Demko Rihter, vanr. prof.
U nastavku će biti predstavljene najznačajnije metode za izračunavanje vrednosti kapitala i to: prinosni metod, tržišni metod, troškovni metod, i ostale metode.

\subsection{Prinosni metod}

Prinosni metod procene polazi od pretpostavke da je vrednost kapitala jednaka sadašnjoj vrednosti projektovanih budućih rezultata (neto dobitka ili neto novčanog toka) koja je uvećana za rezidualnu vrednost.

Ovaj metod se naziva i metodom diskontovanja ostvarenih rezultata (obično neto novčanih tokova). Suština metoda je obračun sadašnje vrednosti budućih neto novčanih tokova koji se moraju diskontovati odgovarajućom diskontnom stopom. U okviru prinosnog metoda postoje dva načina obračuna vrednosti kapitala [2]:

a) Kapitalizovanje ostvarenih rezultata

b) Diskontovanje budućih rezultata

U okviru kapitalizovanja ostvarenih rezultata postoje dve metode [2]:

a) Kapitalizovanje dobiti

b) Kapitalizovanje neto novčanog toka

Ovaj metod se primenjuje u situacijama u kojima se ne očekuje da preduzeće značajnije menja svoje poslovanje u odnosu na postojeće stanje, odnosno kada se budući rezultati mogu projektovati primenom određene stope rasta. Vrednost se dobija deljenjem ostvarenog rezultata poslovanja stopom kapitalizacije [1].

U okviru metode diskontovanja budućih rezultata takođe postoje dve metode [2]:

a) Diskontovani neto novčani tok

b) Diskontovana buduća dobit

Ovaj metod se primenjuje u situacijama u kojima se očekuje da preduzeće značajnije menja svoje poslovanje u odnosu na postojeće stanje, na primer usled promena $u$ strukturi delatnosti ili usled očekivanih promena uslova privređivanja, kao i u situacijama u kojima se mogu projektovati budući rezultati.

Rezultati se projektuju do trenutka u kome se očekuje njihovo stabilizovanje, a zatim se na osnovu stabilizovanog rezultata utvrđuje tzv. terminalna ili rezidualna vrednost. Konačno, projektovani rezultati uključujući i rezidualnu vrednost, se diskontuju ili svode na sadašnju vrednost primenom diskontne stope [1]. 


\subsection{Tržišni metod}

Tržišni pristup u proceni vrednosti preduzeća predstavlja noviji metod u proceni vrednosti kapitala. Osnovna pretpostavka na kojoj se bazira je mogućnost poređenja performansi procenjivanog preduzeća sa performansama sličnih preduzeća. Osnova tržišnog pristupa je u posmatranju aktuelnih cena po kojoj se obavljaju tržišne transakcije $\mathrm{u}$ odnosu na fundamentalne finansijske podatke preduzeća ciji se kapital procenjuje. U okviru ovog koncepta postoje dva pristupa [2]:

a) Metod multiplikatora

b) Metod analize tržišnih transakcija

Metod multiplikatora polazi od pretpostavke da se na bazi odnosa veličine kapitala i neke druge veličine (dobiti, novčanog toka, prihoda i sl.) preduzeća sa kojim se poredi procenjivano preduzeće, dobije koeficijent čijom će se primenom na dobit, novčani tok ili prihod procenjivanog preduzeća dobiti indikacija o vrednosti kapitala [2].

Metod analize tržišnih transakcija podrazumeva obezbeđivanje i analiziranje podataka o tržišnim transakcijama, odnosno o kupovini ili prodaji sličnih preduzeća u prošlosti [2].

\subsection{Troškovni metod}

Troškovni metod procenjuje kapital koristeći ekonomski princip da kupac neće platiti više za određenu imovinu od troškova sticanja imovine jednake koristi, bilo kupovinom ili izgradnjom, osim ukoliko postoje određene neprijatnosti, rizici ili drugi negativni faktori. Troškovni metod procenjuje vrednost kapitala tako što kalkuliše troškove trenutne zamene ili reprodukcije sredstava kojima preduzeće raspolaže. Mogući metodi u okviru ovog pristupa su [3]:

a) Metod neto imovine

b) Metod likvidacione vrednosti

\subsection{Ostale metode}

Pored navedenih metoda postoje još i sledeće metode [1]:
a) Metod viška prinosa
b) Metod novčanog toka prodavca
c) Pravliza procenu
d) Specifični metodi

\section{METODA DISKONTOVANJA NETO NOVČANIH TOKOVA}

Diskontovani novčani tok (DNT) je metoda procene vrednosti kapitala koja se koristi za procenu vrednosti investicija koje se zasnivaju na budućim novčanim tokovima. DNT analiza pokušava da utvrdi vrednost investicije danas, na osnovu projekcija koliko će novca investicija zaraditi u budućnosti.

Ovo se odnosi i na finansijska ulaganja investitora i na vlasnike preduzeća koji žele promene u poslovanju. Diskontovani novčani tok ujedno predstavlja osnovnu metodu za procenu vrednosti kapitala preduzeća i zajedno sa metodom kapitalizacije spada $\mathrm{u}$ prinosne metodu procene.
Dosledna primena ove metode procene zahteva: [1]

a) Izbor definicije novčanog toka,

b) Projektovanje novčanog toka u izabranom periodu,

c) Proračun diskontne stope,

d) Proračun sume sadašnje vrednosti neto novčanog toka u projektovanom periodu,

e) Proračun rezidualne vrednosti,

f) Određivanje konačne vrednosti kapitala preduzeća,

g) Prilagođavanje za vrednost neposlovnih sredstava $\mathrm{i} / \mathrm{ili}$ neangažovanih poslovnih sredstava.

\subsection{Izbor definicije novčanog toka}

Gotovinski tok predstavlja gotovinu ili gotovinske evkivalente koji lako mogu da se konvertuju u gotovinu najduže za 30 dana [4]. Novčani tok obuhvata sve poslovne, finansijske $i$ investicione prilive $i$ odlive sredstava. Postoje dve definicije za izračunavanje novčanog toka:

a) novčani tok posle servisiranja obaveza

b) novčani tok pre servisiranja obaveza

Od izabrane definicije novčanog toka će zavisiti način obračuna diskontne stope.

\subsection{Projektovanje novčanog toka}

Projekcije novčanog toka predstavljaju jedan od najznačajnijih koraka prilikom procene vrednosti kapitala. Od projekcija novčanih tokova zavisi i konačna procenjena vrednost kapitala. Projekcije u ovom radu su vršene za narednih pet godina, a osnovu je činila neto dobit iz bilansa uspeha u projektovanom periodu.

\subsection{Diskontna stopa}

Diskontna stopa je neophodan elemenat $\mathrm{u}$ postupku diskontovanja, odnosno svođenja buduće vrednosti na sadašnju. Potreba za diskontom stopom proizilazi iz činjenice da jedna novčana jedinica danas vredi više nego jedna novčana jedinica sutra, odnosno u budućem periodu. Ovaj fenomen je u literaturi poznat kao vremenska preferencija novca. Utvrđivanje diskontne stope jeste ključna faza u proceni vrednosti kapitala, jer visina ove stope značajno utiče na rezultat procene konačne vrednosti preduzeća.

Postoji nekoliko načina za izračunavanje diskontne stope, a za potrebe ovog rada korišćena je ponderisana prosečna cena kapitala, za čije utvrđivanje je potrebno raspoalagati podacima o ceni sopstvenog kapitala i ceni kreditnih izvora finansiranja, koji se nakon toga ponderišu učešćem u ukupnim izvorima finansiranja preduzeću kako bi se utvrdila diskontna stopa.

\subsection{Rezidualna vrednost}

Rezidualna vrednost predstavlja vrednost koja se odnosi na period poslovanja preduzeća nakon projektovanog perioda od 5 godina, uz pretpostavku da će preduzeće nastaviti da posluje i nakon projektovanog perioda. $\mathrm{U}$ ovom radu rezidualna vrednost je proračunata korišćenjem tzv. Gordonovog modela. 


\section{ULOGA I ZNAČAJ FINANSIJSKE ANALIZE}

Analiza finansijskih performansi predstavlja jednu od najvažnijih faza prilikom analize poslovanja preduzeća. Analiziraju se finansijski izveštaji preduzeća iz prethodnih godina i prave projekcije za narednih nekoliko godina, u praksi najčešće pet godina. Cilj finansijske analize jeste da se stvori slika o budućem poslovanju preduzeća. Neophodno je kombinovati finansijsku analizu sa makroekonomskom analizom, kao i analizom industrije i na ovaj način stvoriti kompletnu sliku o poslovanju preduzeća i njegovom socio-ekonomskom okruženju.

Najznačajniji finansijski izveštaji koji se analiziraju su:
a) Bilans stanja
b) Bilans uspeha
c) Izveštaj o tokovima gotovine

Bilans stanja se uobičajeno definiše kao finansijski izveštaj koji sistematizovano prikazuje stanje imovine, obaveza i kapitala u određenom vremenskom trenutku [5].

Bilans uspeha nam prikazuje strukturu prihoda i rashoda, kao i kakav je bio rezultat poslovanja u posmatranoj godini (prikazom dobitka/gubitka).

Izveštaj o tokovima gotovine pruža informacije o prilivu i odlivu gotovine u poslovnim, investicionim i finansijskim aktivnostima preduzeća.

U okviru analize finansijskih performansi izvršen je pregled najvažnijih racio pokazatelja koji će biti korišćeni u daljem radu.

\section{ISTORIJAT I OPIS POSLOVANJA MEDICINSKE LABORATORIJE JUGOLAB}

Medicinska laboratorija Jugolab osnovana je 14. aprila 2000. godine u Novom Sadu. Registrovana je za vršenje analiza iz oblasti biohemije, mikrobiologije i patohistologije. Danas, 20 godina kasnije, medicinska laboratorija Jugolab predstavlja centralnu laboratoriju lanca od ukupno 27 biohemijskih, mikrobioloških i patohistoloških laboratorija koje posluju od Subotice, Sombora i Apatina na severu, do Čačka i Užica. Zapošljava više od 140 ljudi u 17 gradova i mesta, a posao obavlja na preko $2300 \mathrm{~m}^{2}$ poslovnog prostora.

Biohemijske analize predstavljaju osnovu poslovanja sa učešćem u prihodima od $80 \%$, mikrobiologija učestvuje u prihodima oko $14 \%$, dok patohistologija učestvuje u prihodima oko $6 \%$.

Medicinska laboratorija Jugolab je laboratorija akreditovana standardom SRPS EN ISO 15189:2014.

\section{ANALIZA FINANSIJSKIH PERFORMANSI MEDICINSKE LABORATORIJE JUGOLAB}

U okviru analize finansijskih performansi izvršena je analiza bilansa uspeha, bilansa stanja i najznačajnijih racio pokazatelja u periodu od 2015. god 2019. godine.
Na osnovu bilansa uspeha utvrđeno je da su prihodi porasli sa 143,432,000 dinara u 2015. godini na 262,424,000 dinara u 2019. goodini. Rashodi su stabilno rasli, dok se marža neto dobiti kretala od 7,44\% u 2015 . godini do $12,59 \%$ u 2019. godini poslovanja.

Analizom bilansa stanja utvrđeno je da je stalna imovina porasla tokom godina sa 14 miliona dinara u 2015. godini, na 34,5 miliona dinara u 2019. godini, dok je obrtna imovina bila na nivou od 30 miliona u 2015. godini da bi u 2019. godini iznosila 44 miliona dinara. Ukupni kapital je rastao tokom posmatranog perioda zbog rasta neraspoređene dobiti. Dugoročnih obaveza nije bilo, dok su kratkoročne obaveze prvenstveno obaveze iz redovnog poslovanja.

Racio analiza obuhvatila je racio pokazatelje likvidnosti, zaduženosti, finansijske aktivnosti i profitabilnosti. Na osnovu izračunatih racio pokazatelja likvidnosti zaključak je da je Jugolab u prethodnih 5 godina visoko likvidno preduzeće. Pokazatelji zaduženosti govore da se preduzeće finansira u velikoj meri iz sopstvenih sredstava, konkretno $91 \%$ od ukupnih sredstava je pokriveno sopstvenim kapitalom, što ukazuje da preduzeće u svom poslovanju ne koristi finansijski leveridž. Pokazatelji finansijske aktivnosti nam govore da je preduzeće poboljšalo broj dana naplate potraživanja sa 53 dana na 33 dana, da je ubrzalo iskorišćenje zaliha sa 12,4 na 9.8 , dok je prosečan broj dana isplate obaveza iznosio 20 dana u 2019. godini. Pokazatelji profitabilnosti ukazuju da je stopa povrata na imovinu i kapital u posmatranom periodu bila na visokom nivou, dok se EBITDA marža (eng. Earnings Before Interest Taxes Depreciaton and Amortization) kretala od $14 \%$ do $19 \%$ u posmatranom periodu.

\section{PROJEKCIJA NAJZNAČAJNIJIH FINANSIJSKIH IZVEŠTAJA}

Projektovanje finansijskih izveštaja bilansa uspeha, bilansa stanja i novčanih tokova je izvršeno za petogodišnji period od 2020. godine do 2024. godine.

Projekcijom bilansa uspeha je utvrđeno da ce posledice delovanja Korona virusa usporiti rast prihoda za $10 \%$ u 2020. godini, dok se u narednim godinama projektuje stabilizacija poslovanja i rast prihoda. Očekivani prihodi u 2024. godini iznose $353,689,000$ dinara, uz prosečnu godišnju stopu rasta od $6,1 \%$ u posmatranom periodu. Projektovana marža neto dobiti će se kretati u posmatranom periodu od $11,19 \%$ (2020. godina) do $14,51 \%$ (2024. godina).

Projekcijom bilansa stanja ukupna aktiva preduzeća (stalna i obrtna imovina) je u projektovanom periodu porasla sa 78,707 miliona dinara u 2019. godini na 200,933 miliona dinara u 2024. godini poslovanja, pri čemu se najveći rast odnosi na rast gotovinske pozicije. U okviru pasive osnovni kapital se projektuje u istom iznosu tokom petogodišnjeg perioda, dok se zahvaljujući kontinuiranom rastu neraspoređene dobiti i njihovom pripisivanju glavnici kapitala uvećavaju sopstveni izvori. 
Projekcijom novčanih tokova koji se sastoje iz poslovnih investicionih i finansijskih aktivnosti u okviru novčanih odliva projektovana su godišnja kapitalna ulaganja u iznosu od 4 miliona dinara, kao i isplata dividende od 12 miliona dinara u 2020. godini, dok se u narednim godinama poslovanja projektuje isplata dividende $u$ iznosu od 18 miliona dinara.

Novčani tok se u projektovanom periodu kretao od 26 miliona u 2020. godini do 34 miliona dinara u 2024. godini, sa prosečnom godišnjom stopom rasta od 5,5\%.

\section{PROCENA VREDNOSTI KAPITALA MEDICINSKE LABORATORIJE JUGOLAB}

Procena vrednosti kapitala medicinske laboratorije Jugolab bazirana je na 2 različite metode, i to metodi diskontovanja neto novčanih tokova (DNT) i metodi multiplikatora.

U okviru metode DNT proračunat je tzv. slobodan novčani tok koristeći metodu pre servisiranja dugova koja obuhvata neto dobit, amortizaciju, promene u neto obrtnom kapitalu i kapitalna ulaganja. Slobodni novčani tok je u 2020. godini iznosio 38 miliona dinara, da bi u 2024. godini on bio na nivou od 52 miliona dinara. Nakon proračuna slobodnog novčanog toka, izračunata je diskontna stopa kao prosečna ponderisana cena kapitala, koja obuhvata cenu sopstvenog kapitala i cenu kreditnih izvora finansiranja. Cena sopstvenog kapitala se sastoji iz stope povraćaja bez rizika koja je jednaka stopi prinosa državnih obveznica i stope specifičnog rizika preduzeća. Stopa povraćaja bez rizika iznosi 3,6\% dok proračunata stopa specifičnog rizika preduzeća iznosi $6,58 \%$, odnosno ukupno 10,18\%. Obzirom da se preduzeće finansira iz sopstvenih sredstava, cena sopstvenog kapitala je ujedno i diskontna stopa korišćena za proračun vrednosti kapitala. Diskontovanjem novčanih tokova utvrđena je suma diskontovanih novčanih tokova u projektovanom periodu u iznosu od 159,410,000 dinara. Nakon proračunatih diskontovanih novčanih tokova izvršeno je izračunavanje rezidualne vrednosti Gordonovim modelom. Rezidualna vrednost iznosi 194,040,000 dinara. Ukupna vrednost izračunata metodom DNT iznosi 353,459,000 dinara. Analizom osetljivosti promene diskontne stope utvrđeno je da bi povećanje diskontne stope za samo $1 \%$ umanjilo ukupnu procenjenu vrednost kapitala preduzeća za 50 miliona dinara, dok bi smanjenje diskontne stope za $1 \%$ povećalo procenjenu vrednost kapitala za čak 70 miliona dinara.

Metod primene multiplikatora obuhvatio je korišćenje EV/EBITDA multiplikatora kako bi se dobila konačna vrednost preduzeća. Multiplikator EV/EBITDA prema Damodaranu iznosi 13,31, dok je projektovana EBITDA kojom se multiplikator množi na nivou od 35,746,000 dinara. Konačna vrednost izračunata metodom multiplikatora iznosi 475,779,260 dinara.
Kombinacijom obe metode i dodavanjem učešća (pondera) od $90 \%$ metodi DNT i $10 \%$ metodi multiplikatora utvrđena je konačna vrednost preduzeća od 365,691,026 dinara.

\section{ZAKLJUČAK}

Potreba za procenom vrednosti kapitala se učestalo pojavljuje u poslovanju velikog broja preduzeća, naročito u zemljama sa razvijem tržištem kapitala. Procena vrednosti kapitala predstavlja veoma kompleksan process koji zahteva poznavanje makroekonomskih, ali i mikroekonomskih faktora poslovanja, kao i stručnost iskustvo $\mathrm{u}$ analizi finansijskih izveštaja. Greške $\mathrm{u}$ projektovanju novčanih tokova kao i obračunu diskontne stope mogu dovesti do drastičnog povećanja ili smanjenja vrednosti kapitala preduzeća koje je predmet procene. Iz navedenih razloga, objektivnost je veoma važna osobina koju je neophodno imati prilikom procene vrednosti kapitala. Procenu vrednosti kapitala uglavnom rade timovi profesionalaca sa dugogodišnjim iskustvom i velikim znanjem, kako bi se smanjila mogućnost pojave greške.

\section{LITERATURA}

[1] Leko, V., Vlahović, A., Poznanić, V., (1997). Procena vrednosti kapitala, Ekonomski institut, Beograd.

[2] Grdinić, V., (2019). Diskontna stopa kao faktor procene vrednosti kapitala, Doktorska disertacija, Novi Sad.

[3] IVSC, International Valuation Standards (IVS), 2020. [4] Anđelić, G., Đaković, V., (2017). Osnove investicionog menadžmenta, FTN, Novi Sad.

[5] Nerandžić B., Perović V., (2013). Upravljačko računovodstvo, FTN, Novi Sad

\section{Kratka biografija:}

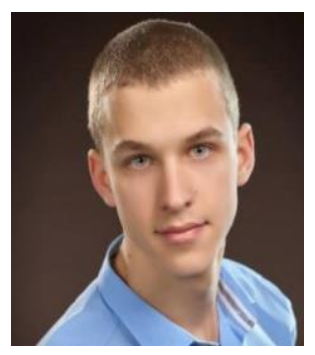

Predrag Vujatov rođen je 1996. god u Novom Sadu. Diplomu o visokom obrazovanju stekao je na Fakultetu tehničkih nauka u Novom Sadu. Master rad na temu „Analiza finansijskih performansi u funkciji vrednovanja kapitala medicinske laboratorije Jugolab" iz oblasti Inženjerskog menadžmenta odbranio je na Fakultetu tehničkih nauka 2020. godine. 